\title{
Two-dimensional mapping of Asia Pacific destinations combining tourism and economic indicators
}

\author{
Oscar Claveria* \\ AQR-IREA, University of Barcelona, 08034 Barcelona, Spain
}

\begin{abstract}
The present study aims to cluster five Asia Pacific destinations (Cambodia, Hong Kong, Indonesia, the Philippines, and Singapore) with respect to other countries according to the evolution of the main tourism and economic indicators over the period between 2000 and 2014. By assigning a numerical value to each country corresponding to its position, we summarize all the information into two components ("tourism expenditure and profitability of tourism activity" and "tourism development and economic growth") using different multivariate techniques for dimensionality reduction. By means of perceptual maps, we find that the five Asia Pacific destinations can be clustered into three different groups: Hong Kong and Singapore, which are the most mature markets; Indonesia and the Philippines, with moderate growth rates in most variables; and Cambodia, with top positions in all variables, showing a huge potential in terms of growth and tourism development and the challenges derived therefrom.
\end{abstract}

Keywords: Tourist destinations; Asia Pacific; Positioning; Categorical Principal Components Analysis (CATPCA); Multidimensional Scaling (MDS)

\footnotetext{
* Corresponding author. Tel.: +34-934021825; Fax.: +34-934021821. Department of Econometrics, Statistics and Applied Economics. University of Barcelona, Diagonal 690, 08034 Barcelona, Spain. Email: oclaveria@ub.edu
} 


\section{Introduction}

Tourism is one of the fastest-growing economic sectors in the world, and it has turned into a key driver of socio-economic development. An ever-increasing number of destinations worldwide have opened up to tourism. The market share of emerging economies increased from $30 \%$ in 1980 to $45 \%$ in 2014. Asia and the Pacific, which accounts for $23 \%$ of worldwide arrivals and $30 \%$ of receipts, is the region expected to experience the strongest growth during the next decade, together with Africa and the Middle East (UNWTO, 2015). Within this increasingly competitive market, tourist destinations have to make major efforts in order to develop and manage their brand.

In this research we present a method to position and cluster five Asia Pacific destinations with respect to other fifteen international markets according to the evolution of their main tourism and economic indicators. We aim to contribute to tourism research literature by analysing how the dynamic interactions between the main tourism and economic indicators ultimately affected the positioning of destinations since the turn of the century. Li et al. (2013) note the importance of the economic dimension in determining destinations competitiveness. By means of several multivariate techniques for dimensionality reduction, we summarized all information into two components that allow us to map five Asia Pacific destinations in relation to other fifteen international markets.

First, we conduct a descriptive analysis of the annual percentage growth rates of the official indicators over the period comprised between 2000 and 2014. We complement the analysis with a graphical representation of the co-movements between tourism variables and economic growth. Second, we rank the twenty tourist destinations regarding their average growth rate over the sample period, which indirectly introduces a dynamic perspective into the analysis. Finally, by assigning a numerical value to each destination corresponding to its position in the rankings, we cluster the destinations by means of two multivariate techniques of optimal scaling: Multidimensional Scaling (MDS) and Categorical Principal Component Analysis (CATPCA).

As far as we know, there is only one previous study that compares the performance of both techniques in the positioning of tourist destinations (Claveria \& Poluzzi, 2017). The authors used MDS and CATPCA to map the world's top ten destinations, and found that they could be grouped into language spheres. We extend the analysis to cluster the main South-East Asia destinations. 
We focus the study on five destinations from Asia and the Pacific (Cambodia, Hong Kong, Indonesia, Philippines and Singapore), and compare them to other fifteen international destinations: Greece and Israel, from the Southern and Mediterranean Europe region; Finland, Norway and Sweden, from Northern Europe; Estonia and Poland, from Central and Eastern Europe; the Dominican Republic, from the Caribbean; Costa Rica, El Salvador and Panama, from Central America; Chile, from South America; Morocco and Tunisia, from North Africa; and Egypt, from the Middle East. We use the UNWTO regional classification. The selection criteria is based on the availability of secondary data for the sample period, under the constraint that all five UNWTO regions are represented (Table 1).

Table 1. Frequency distribution of international inbound tourism (2014)

\begin{tabular}{lcclcc}
\hline Destination & $\begin{array}{c}\text { Annual } \\
\text { mean }\end{array}$ & $\begin{array}{c}\text { Relative } \\
\text { frequency } \\
\text { worldwide }\end{array}$ & Destination & $\begin{array}{c}\text { Annual } \\
\text { mean }\end{array}$ & $\begin{array}{c}\text { Relative } \\
\text { frequency } \\
\text { worldwide }\end{array}$ \\
\hline Hong Kong & 27,770 & $2.392 \%$ & Dominican Rep. & 5,141 & $0.443 \%$ \\
Greece & 22,033 & $1.898 \%$ & Norway & 4,855 & $0.418 \%$ \\
Poland & 16,000 & $1.378 \%$ & Philippines & 4,833 & $0.416 \%$ \\
Singapore & 11,864 & $1.022 \%$ & Cambodia & 4,503 & $0.388 \%$ \\
Sweden & 10,522 & $0.906 \%$ & Chile & 3,674 & $0.316 \%$ \\
Morocco & 10,283 & $0.886 \%$ & Israel & 2,927 & $0.252 \%$ \\
Egypt & 9,628 & $0.829 \%$ & Estonia & 2,918 & $0.251 \%$ \\
Indonesia & 9,435 & $0.813 \%$ & Costa Rica & 2,527 & $0.218 \%$ \\
Tunisia & 6,069 & $0.523 \%$ & Panama & 1,745 & $0.150 \%$ \\
Finland & 5,710 & $0.492 \%$ & El Salvador & 1,345 & $0.116 \%$ \\
\hline
\end{tabular}

Note: Tourist arrivals are measured in thousands.

This research differs from previous destination positioning studies in several respects. On the one hand, due to the lack of attention paid to economic return and the omission of economic indicators in most tourism studies (Song et al., 2012), we introduce economic information in the analysis. Specifically, we incorporate the Gross Domestic Product (GDP), total inbound expenditure over GDP, and the Human Development Index (HDI). On the other hand, since most tourism variables are nonstationary due to the steady growth in tourism (Chu et al., 2014), we use annual percentage growth rates of the variables to avoid the issues derived from working with non-stationary time series. Li et al. (2013) note the importance of working with growth rates instead of levels. The fact that we exclusively make use of official data, combining tourism indicators provided by the World Tourism Organization (UNWTO), and economic information from the World Bank, makes this study replicable to other destinations. 
Data from the UNWTO include the annual number of international overnight visitors, total expenditure, inbound expenditure over GDP, total number of rooms, and the percentage of the occupancy rates. With this information, we calculate the ratio of expenditure per tourist as a proxy for tourism profitability. We analyse the evolution of these indicators during the period comprised between 2000 and 2014.

The remainder of the study is organized as follows. The next section provides a review of the existing literature. Section 3 describes the data set. In Section 4 we rank the destinations and present the results of the multivariate analysis. Finally, conclusions are presented in Section 5.

\section{Literature review}

The factors that affect the demand for tourism range from politics to economics. The macroeconomic environment can be described by several economic indicators. The effects of economic indicators in the hospitality industry and tourism have been analysed for a set of economic variables. Lee \& Ha (2012) found a positive relation between GDP and the sales of the restaurant industry. Pranić et al. (2012) obtained a positive correlation between the presence of US hotel firms abroad and market interconnectedness, and a non-significant relation for foreign direct investment and tourism flows. These results contrast with those of Novak et al. (2011), who found a positive and significant correlation between the three variables and the presence of foreign hotels in Croatia.

Wang (2009) has noted the importance of identifying the key factors that influence tourism demand in order to effectively understand changes and trends in the tourism market, and create competitive advantages for the tourism industry. Mohammed et al. (2015) have also stressed the need of further research regarding the effect of individual economic variables in the hospitality industry.

The contribution of tourism to economic growth, as well as to destination competitiveness, has been extensively analysed in the tourism literature (Brida et al., 2016; Pérez-Rodríguez et al., 2015; Chou, 2013; Croes, 2011; Schubert et al., 2011; Schubert \& Brida, 2009; Capó et al., 2007; Crouch \& Richie, 2006; Oh, 2005; Durbarry, 2004; Balaguer \& Cantavella-Jordá, 2002). Recent literature highlights the role of capital formation, arguing that the mechanism underlying tourism's welfare-promoting effect heavily relies on capital goods imports (Nowak et al., 2007; Cortés-Jiménez et al. 
2011). Foreign direct investment, trade volume, and exchange rates have also proved to be linked to tourism (Santana-Gallego et al., 2010, 2011; Wong \& Tang, 2010).

These interdependences have been addressed by means of vector autoregressions and co-integration techniques (Seo et al., 2010; Torraleja, 2009), but few studies have made use of multivariate techniques (Chandra \& Menezes, 2001). By reducing the dimensionality in a dataset, multivariate interdependency techniques are used to detect underlying relationships between variables. There are several multivariate techniques for dimensionality reduction: cluster analysis, multiple correspondence analysis (MCA), exploratory factor analysis (EFA), confirmatory factor analysis (CFA), principal components (PCA), etc. For a detailed description of these techniques see Hair et al. (2009), and Jolliffe (2002).

Dimensionality reduction techniques have been used in a wide range of tourism studies: from image and perception analyses to motivation studies (Park \& Yoon, 2009). Arimond \& Elfessi (2001) used MCA to spatially map attributes from categorical survey data, and then cluster analysis to identify market segments. In a recent study, Marcussen (2014) reviewed 64 papers that apply MDS to tourism research, finding that the most common topics were image and positioning of destinations. Zins (2010) depicted destination images of ten different countries from the perspective of two traveller segments via MDS analysis. For a review of the literature on destination image, see Pike (2002).

MDS is also known as Principal Coordinates Analysis or Torgerson scaling (Torgerson, 1952). MDS is a multivariate analytical procedure that allows to visualize the level of similarity between individuals based on the proximity of individuals to each other in a generated map. Perceptual maps allow the visualization of the strengths and weaknesses of destinations. See Borg \& Groenen (2005) and Fentom \& Pearce (1988) for a comprehensive overview of MDS.

The first application of MDS to tourism destinations was that of Wish et al. (1970). Since then, a large number of studies have analysed the positioning of destinations by means of MDS (Li et al., 2015; Marcussen, 2014; Leung \& Baloglu, 2013; Kayar \& Kozak, 2010; Gursoy et al., 2009; Uysal et al., 2000; Andreu et al. 2000; Kim, 1998; Crompton et al., 1992).

Haahti (1986) compared the relative status of Finland as a summer holiday destination compared to nine European competitors. Applying a two-dimensional MDS analysis, Gartner (1989) clustered four American states with similar tourism and recreation attributes. Kim \& Agrusa (2005) positioned seven honeymoon destinations 
according to the perception of Korean tourists regarding eight attributes. Kim et al. (2005) used MDS to identify the position of overseas golf tourism destinations. Omerzel (2006) analysed the competitiveness of Slovenia as a tourist destination regarding the ratings for 85 indicators grouped into six categories.

Lozano \& Gutierrez (2011) applied MDS to analyse 25 European destinations. Marcussen (2011) combined MDS with FA to position and group 33 European destinations in relation to each other. Using official data from Eurostat regarding monthly overnight stays from 1998 to 2009, the author found that European destinations could be grouped by major language spheres. Claveria \& Poluzzi (2017) arrived to a similar conclusion for the world's top destinations.

In a similar study, Leung \& Baloglu (2013) evaluated the destination competitiveness of sixteen Asia Pacific destinations, generating three-dimensional perceptual maps, and using cluster analysis to identify groupings on the maps. Recently, Li et al. (2015) analysed the position of the United States (US) against its major nonAsian competitors. By combining MDS, MCA, and logistic regression, the authors found that the US holds a unique position in relation to its competitor destinations. MDS has also been applied in other tourism studies. Chhetri et al. (2004) identified the underlying dimensions influencing visitor experiences in nature-based tourism destinations. For a comprehensive overview of MDS, see Borg et al. (2013), and Borg \& Groenen (2005).

Recent developments in multivariate analysis focus on dealing with nonlinear relationships in data. PCA has been extended by using autoassociative neural networks (Kramer, 1991), principal curves and manifolds (Hastie \& Stuetzle, 1989), and kernel approaches (Schölkopf et al., 1998). Another machine learning technique are SelfOrganizing Maps (SOMs) (Kohonen, 2001). SOMs can be regarded as a nonlinear generalization of PCA (Liu \& Weisberg, 2005). SOM analysis is used to generate visual representations of data that allow to disclose unknown patterns. While SOMs are starting to be used in economic studies (Claveria et al., 2016; Sarlin \& Peltonen, 2013), to our knowledge, the only application in tourism is that of Bloom (2005), who uses a SOM for segmenting the inbound tourism demand to Cape Town.

CATPCA, also known as nonlinear PCA, represents another development in nonlinear dimensionality reduction. See Gifi (1990) for a historical overview, and Linting et al. (2007) for an exhaustive treatment of nonlinear PCA. CATPCA does not assume that the relationships between variables are linear, and can discover nonlinear relationships between variables. Another advantage of CATPCA over standard PCA, is 
that it allows incorporating nominal and ordinal variables. In spite of these features, few studies have applied CATPCA in tourism research (Correia et al., 2007; Green, 2005).

In order to cover this deficit, we compare the performance of CATPCA and MDS in the positioning of twenty destinations based on the rankings regarding different official indicators that combine tourism and economic information. These procedures are used to reduce the dimensionality of data by transforming the original set of correlated variables into a smaller set of uncorrelated variables. These new variables are also known as factors, and can be interpreted as synthetic indicators that maintain the original ordinal structures.

\section{Data}

The dataset is comprised of two major sources of information. On the one hand, we use official data from the Compendium of Tourism Statistics provided by the UNWTO (http://www2.unwto.org/content/data-0): overnight visitors (thousands), total expenditure (US\$ millions), occupancy rate (\%), rooms, and inbound expenditure over GDP (\%). From these set of data, we calculate the ratio of total expenditure per tourist.

On the other hand, we add economic information in the form of the GDP at market prices of each destination based on constant local currency provided by the World Bank (http://data.worldbank.org/indicator/NY.GDP.MKTP.KD.ZG). Finally, we include the HDI (http://hdr.undp.org/en/content/human-development-index-hdi) which is a composite indicator of life expectancy, education, and income per capita that allows us to capture the relationship between tourism and development beyond a strictly economic sense.

First, we conduct a descriptive analysis of the annual percentage growth rates of the variables. Given that growth rates are dimensionless measures of the amount of variation of a specific variable from one year to another in percentage terms, we are able to undertake a comparative analysis of the evolution of the different tourism indicators (Table 2 and Table 3).

In Table 2 we present a descriptive analysis of the variables for the five destinations from the Asia Pacific region. Cambodia is the destination that shows the highest average growth rates for most variables, with the exception of the expenditure per tourist, for which it obtains the lowest average rate. On the other extreme, Hong Kong presents the highest average rate in terms of expenditure per tourist. Philippines is the destination 
that shows the lowest average growth rates for most variables (total expenditure, occupancy, and GDP). Occupancy rates and GDP growth do not vary across countries as much as the rest of the variables. Hong Kong shows higher dispersion for most of the variables than the rest of the destinations.

Table 2. Annual percentage growth rates of UNWTO tourism indicators - Asia Pacific destinations

\begin{tabular}{|c|c|c|c|c|c|}
\hline Variable & Cambodia & Hong Kong & Indonesia & Philippines & Singapore \\
\hline \multicolumn{6}{|c|}{ Expenditure per tourist } \\
\hline Mean & -0.6 & 9.4 & 2.6 & 1.5 & 4.4 \\
\hline Std. Dev. & 8.1 & 41.2 & 11.6 & 17.8 & 10.5 \\
\hline \multicolumn{6}{|c|}{ Overnight visitors } \\
\hline Mean & 19.1 & 9.3 & 5.0 & 5.8 & 5.9 \\
\hline Std. Dev. & 14.9 & 11.6 & 8.2 & 8.8 & 13.2 \\
\hline \multicolumn{6}{|c|}{ Total expenditure } \\
\hline Mean & 18.4 & 19.3 & 8.1 & 7.9 & 10.7 \\
\hline Std. Dev. & 18.0 & 44.6 & 17.1 & 23.2 & 19.0 \\
\hline \multicolumn{6}{|c|}{ Inbound exp./GDP } \\
\hline Mean & 6.9 & 14.5 & -3.2 & -1.5 & 0.7 \\
\hline Std. Dev. & 15.8 & 41.7 & 19.9 & 17.3 & 11.3 \\
\hline \multicolumn{6}{|l|}{ Rooms } \\
\hline Mean & 11.0 & 5.4 & 4.4 & 12.4 & 3.4 \\
\hline Std. Dev. & 5.8 & 3.4 & 3.2 & 51.5 & 3.3 \\
\hline \multicolumn{6}{|c|}{ Occupancy } \\
\hline Mean & 3.0 & 1.3 & 1.8 & 1.0 & 1.3 \\
\hline Std. Dev. & 4.0 & 9.3 & 2.9 & 5.2 & 8.4 \\
\hline \multicolumn{6}{|l|}{ GDP } \\
\hline Mean & 7.9 & 4.1 & 5.3 & 5.1 & 5.7 \\
\hline Std. Dev. & 2.9 & 3.2 & 0.8 & 1.8 & 4.3 \\
\hline
\end{tabular}

Notes: Statistics are conducted for the sample period: 2000-2014.

In Table 3 we present a summary of the descriptive analysis, comparing the results of the five Asia Pacific destinations to the other fifteen markets. In Asia Pacific destinations all variables experience an increase on average. Total expenditure is the indicator that presents the highest growth. But if we look at the evolution of the expenditure per tourist (3.45\%), it is significantly lower than the increase of inbound tourism during the sample period $(9.02 \%)$. While the occupancy rate increased by $1.66 \%$ in Asia Pacific destinations, it decreased by $0.26 \%$, in the rest of the countries. 
Table 3. Annual percentage growth rates of the UNWTO tourism indicators - Summary (2000-2014)

\begin{tabular}{lcccc}
\hline Variable & Mean & $\begin{array}{c}\text { Standard } \\
\text { Deviation }\end{array}$ & Minimum & Maximum \\
\hline Expenditure per tourist & 3.45 & 21.25 & -54.88 & 146.53 \\
Asia Pacific destinations & 2.37 & 11.73 & -45.21 & 50.56 \\
$\begin{array}{l}\text { All other destinations } \\
\text { Overnight visitors }\end{array}$ & & & & \\
Asia Pacific destinations & 9.02 & 12.47 & -19.68 & 50.50 \\
All other destinations & 5.58 & 13.49 & -50.52 & 123.17 \\
Total expenditure & & & & \\
Asia Pacific destinations & 12.87 & 26.24 & -51.29 & 162.59 \\
All other destinations & 7.46 & 12.96 & -38.10 & 43.88 \\
Inbound expenditure / GDP & & & & \\
Asia Pacific destinations & 3.48 & 23.96 & -53.60 & 148.72 \\
All other destinations & 0.41 & 12.88 & -42.24 & 49.87 \\
Rooms & & & & \\
Asia Pacific destinations & 7.31 & 22.97 & -45.34 & 126.18 \\
All other destinations & 3.71 & 5.24 & -12.64 & 36.21 \\
Occupancy & & & & \\
Asia Pacific destinations & 1.66 & 6.32 & -16.67 & 25.71 \\
All other destinations & -0.26 & 9.31 & -35.71 & 33.82 \\
GDP & & & & \\
Asia Pacific destinations & 5.60 & 3.06 & -2.46 & 15.24 \\
All other destinations & 3.41 & 3.38 & -14.74 & 12.11 \\
\hline N S Stscs & & & & \\
\hline
\end{tabular}

Notes: $\quad$ Statistics are conducted for the five Asia Pacific destinations during the sample period: 20002014.

We complete the descriptive analysis with a graphical analysis of the evolution of overnight visitors in each destination and economic growth. In Fig. 1 we observe that the impact of the 2008 financial crisis on tourism growth only lasted for a year, as in 2010 tourist arrivals started growing again in all destinations except Chile. This result is in line with previous research by Song et al. (2011) and Singh et al. (2014).

The evolution of overnight visitors and worldwide inbound tourism seems positively correlated in most destinations. Nevertheless, these co-movements are more evident in the Scandinavian countries, Hong Kong or the Philippines than in Egypt or Panama, which show huge oscillations in the evolution of inbound tourism. The rebound of overnight visitors in Norway, Poland and Sweden occurred a year before than in the rest of destinations. Whereas in some countries like the Dominican Republic, the evolution of inbound tourism seems to advance that of total inbound tourism, in others like Greece, there seems to be a one-year lag. 
Fig. 1. Overnight visitors in each country vs. Total inbound tourists (2000-2014)

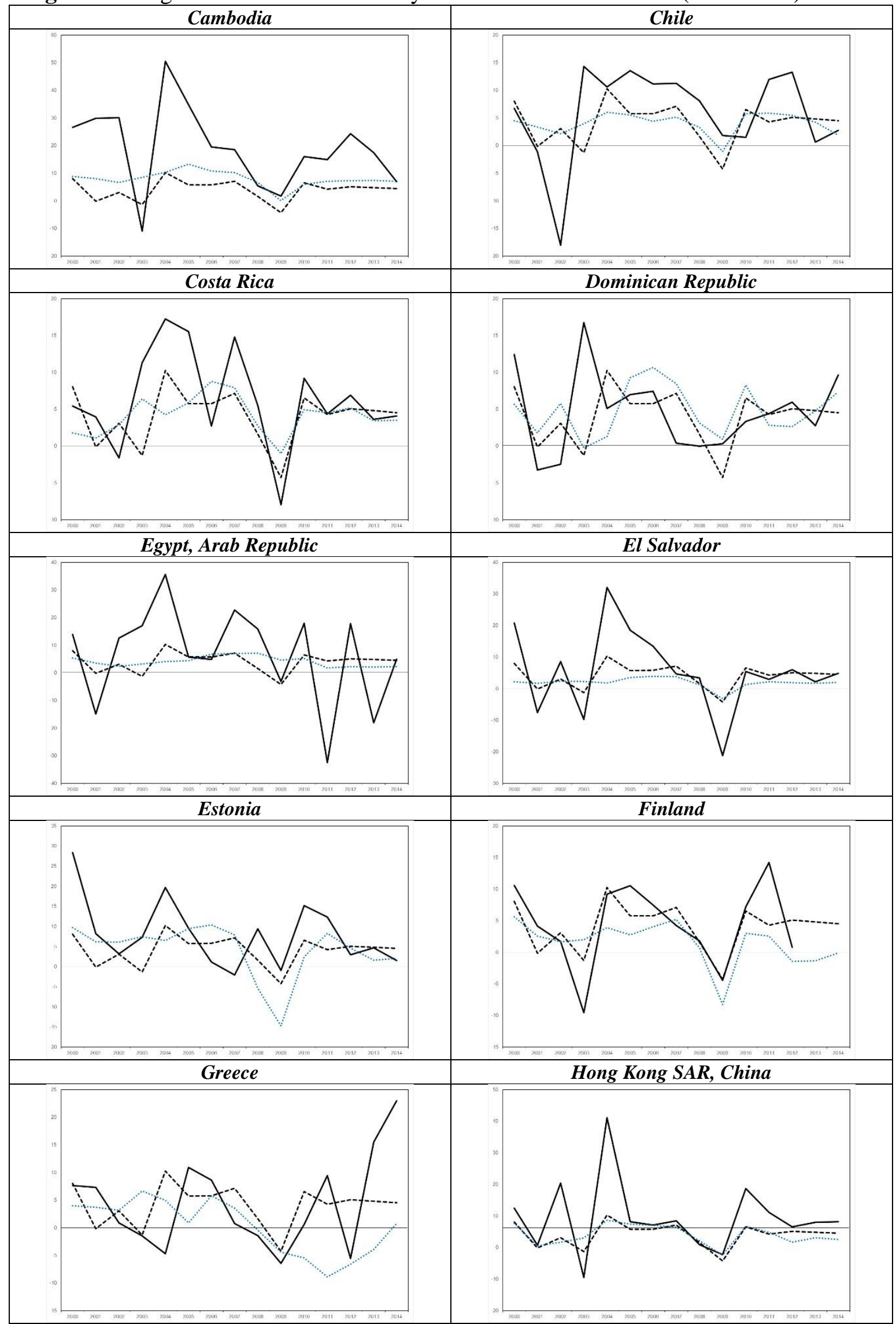

1. Note: Compiled by the author. The black line represents the annual percentage growth rate of international overnight visitors in each country. The black dotted line represents the growth rate of total inbound tourism (overnight visitors worldwide). The grey dotted line represents the annual percentage growth rate of GDP in each country. 
Fig. 1 (cont.). Overnight visitors in each country vs. Total inbound tourists (2000-2014)

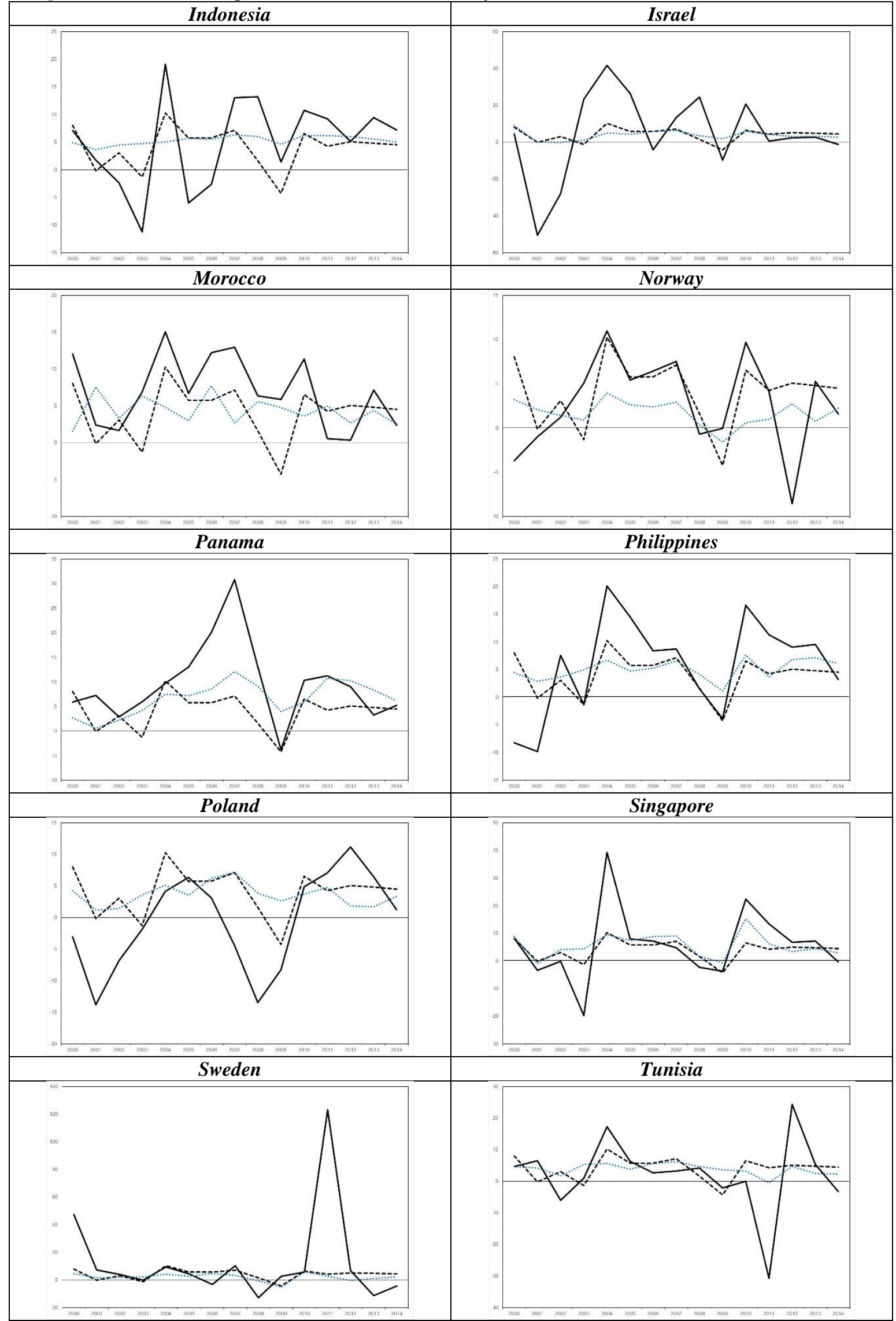

2. Note: Compiled by the author. The black line represents the annual percentage growth rate of international overnight visitors in each country. The black dotted line represents the growth rate of total inbound tourism (overnight visitors worldwide). The grey dotted line represents the annual percentage growth rate of GDP in each country. 
Regarding the five Asia Pacific destinations, Fig. 1 shows very different patterns in each destination. While the annual tourism growth rate in Cambodia is among the highest in the world (Chens et al., 2008), the development of the tourism industry in Cambodia is still incipient, and regarded as a source of foreign exchange (Chheang, 2008). Reimer \& Walter (2013) note that in spite of the increasing importance of tourism for the Cambodian economy, the country is still overly dependent on the single tourism site of Angkor Wat. Travel and tourism's direct contribution to the global Cambodian economy represented $10.2 \%$ of global GDP in 2013; the highest in the South-East Asia region (WTTC, 2014).

Another aspect that stands out is the sharp fall in the annual percentage growth rate of inbound tourists to Hong Kong in 2003 due to the severe acute respiratory syndrome (SARS) epidemic. Au et al. (2005) and Lo et al. (2006) evaluated the effect of SARS on the Hong Kong tourism industry. Hong Kong's position as a gateway to China conditions the duration of the stay, and generates a difference between short haul and long haul visitors (Bao \& Mckercher, 2008). Law and Au (1999) outlined the increasing importance of Japanese tourist in Hong Kong after China, the US, Taiwan and South Korea. Travel and tourism's direct contribution to Hong Kong's global economy represented $9.1 \%$ of global GDP in 2014, the second of the North-East Asia region (WTTC, 2015).

Singapore is one of Hong Kong's principal competitors together with Macau. Both destinations have a similar size, a comparable economic role, and are a gateway for part of the region (Li et al., 2013). In both destinations, inbound tourism is highly dependent on the Asian market. As both are small destinations with a high population density, and with little natural resources to develop, a more diverse tourism experience, they rely on shopping (Wong \& Law, 2003; Choi et al., 1999; Heung \& Qu, 1998), cultural and culinary tourism (Horng \& Tsai, 2012; Okumus et al., 2007), international conferences (Qu et al., 2000), and medical tourism (Li et al., 2013, Ye et al., 2011). The relative contribution of tourism to GDP in Singapore was 4.9\% in 2014 (WTTC, 2015).

Tourism in Indonesia is also an important component of the Indonesian economy. It amounted to $3.2 \%$ of GDP in 2014 (WTTC, 2015). The vast archipelago, with more than 17,000 islands, has in nature and cultural diversity two of its major tourism components. Singapore, Malaysia, China, Australia, and Japan are the top five sources of visitors to Indonesia. In the period 1997-2002, Indonesia experienced ten major shocks that received widespread international publicity and resulted in sharply reduced 
activity in the tourism sector (Prideaux et al., 2003). Pambudi et al. (2009) estimated the short-run effect of a decline in tourism following the 2002 Bali bombings on the Indonesian economy. Tourism is highly concentrated: Bali, Jakarta, and Yogyakarta are some of its most popular destinations.

The Philippines is also an archipelagic country, composed of more than 7,000 islands. Like Indonesia, the Philippines is known for having a rich biodiversity, which is the main tourist attraction of the country. Tourism is also highly concentrated in few destinations such as El Nido in Palawan, Boracay, Cebu, and Manila. Since 2010, South Korea has been the largest source of visitors to the Philippines, followed by the US, Japan, China, Australia, Taiwan, and Canada. Tourism is a pillar of the Philippine economy (Maguigad, 2013), with an annual contribution to GDP of approximately $6 \%$ (Roxas \& Chadee, 2013).

It can be seen that each destination faces different challenges. The objectives of the national tourism administrations in all five destinations include increasing the competitiveness and the sustainability of the sector in the long run, but the emphasis and the type of initiatives differ across destinations. The importance of tourism policies in the development of the tourism industry has been widely acknowledged (Tang, 2017; Dwyer et al., 2010; Hassan, 2000; Crouch \& Ritchie, 1999). Meng et al. (2013) have recently assessed tourism policies in Singapore.

\section{Multivariate analysis}

\subsection{Ranking of destinations}

In this section we rank the twenty destinations according to the average annual growth experienced over the period comprised from 2000 to 2010 for each variable (Table 4).

The rankings in Table 4 confirm some of the results of the previous section. Cambodia is in the top position regarding the average growth in GDP, HDI, overnight visitors, and occupancy, but the last in terms of expenditure per tourist. Hong Kong is in the first position with respect to the average growth of the expenditure per tourist and the inbound expenditure over GDP, and in the top positions for most of the indicators. Similarly to Singapore, which is in the fourth position regarding the growth in the expenditure per tourist. On the other extreme, Indonesia is in the second lowest position 
in terms of the average growth of inbound expenditure over GDP, and together with Philippines occupy positions beyond the median for most tourist indicators.

Table 4

Ranking of destinations - Average annual percentage growth rates (2000-2014)

\begin{tabular}{|c|c|c|c|c|c|c|c|}
\hline $\begin{array}{l}\text { Expenditure } \\
\text { per tourist }\end{array}$ & $\begin{array}{l}\text { Overnight } \\
\text { visitors }\end{array}$ & $\begin{array}{c}\text { Total } \\
\text { expenditure }\end{array}$ & $\begin{array}{l}\text { Inbound } \\
\text { expenditure } \\
\text { per GDP }\end{array}$ & Rooms & Occupancy & GDP & HDI \\
\hline 1 & 2 & 3 & 4 & 5 & 6 & 7 & 8 \\
\hline Hong Kong & Cambodia & Hong Kong & Hong Kong & Philippines & Cambodia & Cambodia & Cambodia \\
\hline Panama & Sweden & Cambodia & Cambodia & Cambodia & Panama & Panama & Morocco \\
\hline Poland & Panama & Panama & Panama & Estonia & Indonesia & Singapore & Indonesia \\
\hline Singapore & Hong Kong & Singapore & Estonia & Poland & Estonia & Indonesia & Singapore \\
\hline El Salvador & Estonia & Morocco & El Salvador & Egypt & Singapore & Philippines & Egypt \\
\hline Norway & Morocco & Estonia & Morocco & Hong Kong & Hong Kong & Dom. Rep. & Chile \\
\hline Finland & Egypt & El Salvador & Sweden & Morocco & Sweden & Morocco & El Salvador \\
\hline Morocco & Costa Rica & Sweden & Greece & El Salvador & Philippines & Estonia & Tunisia \\
\hline Indonesia & Chile & Indonesia & Singapore & Chile & Dom. Rep. & Costa Rica & Estonia \\
\hline Estonia & Singapore & Philippines & Dom. Rep. & Panama & Costa Rica & Egypt & Hong Kong \\
\hline Philippines & Philippines & Finland & Finland & Indonesia & Chile & Hong Kong & Panama \\
\hline Sweden & El Salvador & Chile & Costa Rica & Singapore & Poland & Chile & Dom. Rep. \\
\hline Greece & Indonesia & Norway & Philippines & Costa Rica & El Salvador & Tunisia & Costa Rica \\
\hline Tunisia & Dom. Rep. & Costa Rica & Norway & Dom. Rep. & Norway & Israel & Greece \\
\hline Dom. Rep. & Finland & Egypt & Chile & Norway & Tunisia & Poland & Philippines \\
\hline Chile & Israel & Dom. Rep. & Egypt & Greece & Israel & Sweden & Poland \\
\hline Israel & Greece & Poland & Poland & Sweden & Finland & El Salvador & Israel \\
\hline Costa Rica & Norway & Greece & Tunisia & Tunisia & Greece & Norway & Finland \\
\hline Cambodia & Tunisia & Tunisia & Indonesia & Israel & Morocco & Finland & Norway \\
\hline Egypt & Poland & Israel & Israel & Finland & Egypt & Greece & Sweden \\
\hline
\end{tabular}

Notes: HDI stands for the annual average growth rate of the Human Development Indicator during 2000-2014. Dom. Rep. stands for the Dominican Republic.

\subsection{Positioning of destinations}

By assigning a numerical value to each destination corresponding to its ranking in Table 4, we generate a set of categorical data that we use to map the different destinations. The grouping of all destinations is done by means of two optimal scaling 
techniques for categorical data: CATPCA and MDS, using IBM SPSS Statistics 24 (Meulman et al., 2012).

Both techniques allow us to reduce the information contained in Table 4 into two dimensions. We have used the Kaiser-Guttman method (Guttman, 1954; Kaiser, 1960; Yeomans \& Golder, 1982) in order to determine the number of factors to retain. According to this criterion, only the factors that have eigenvalues greater than one are retained for interpretation. Eigenvalues represent the amount of variance accounted for by a specific component. Each component has an eigenvalue, so the sum of all eigenvalues equals the number of variables in a component analysis. In the screeplot of Fig. 2 we graph the eigenvalues of the correlation matrix of the quantified variables. We can observe that only the first two factors have eigenvalues larger than the unity.

Fig. 2. Screeplot

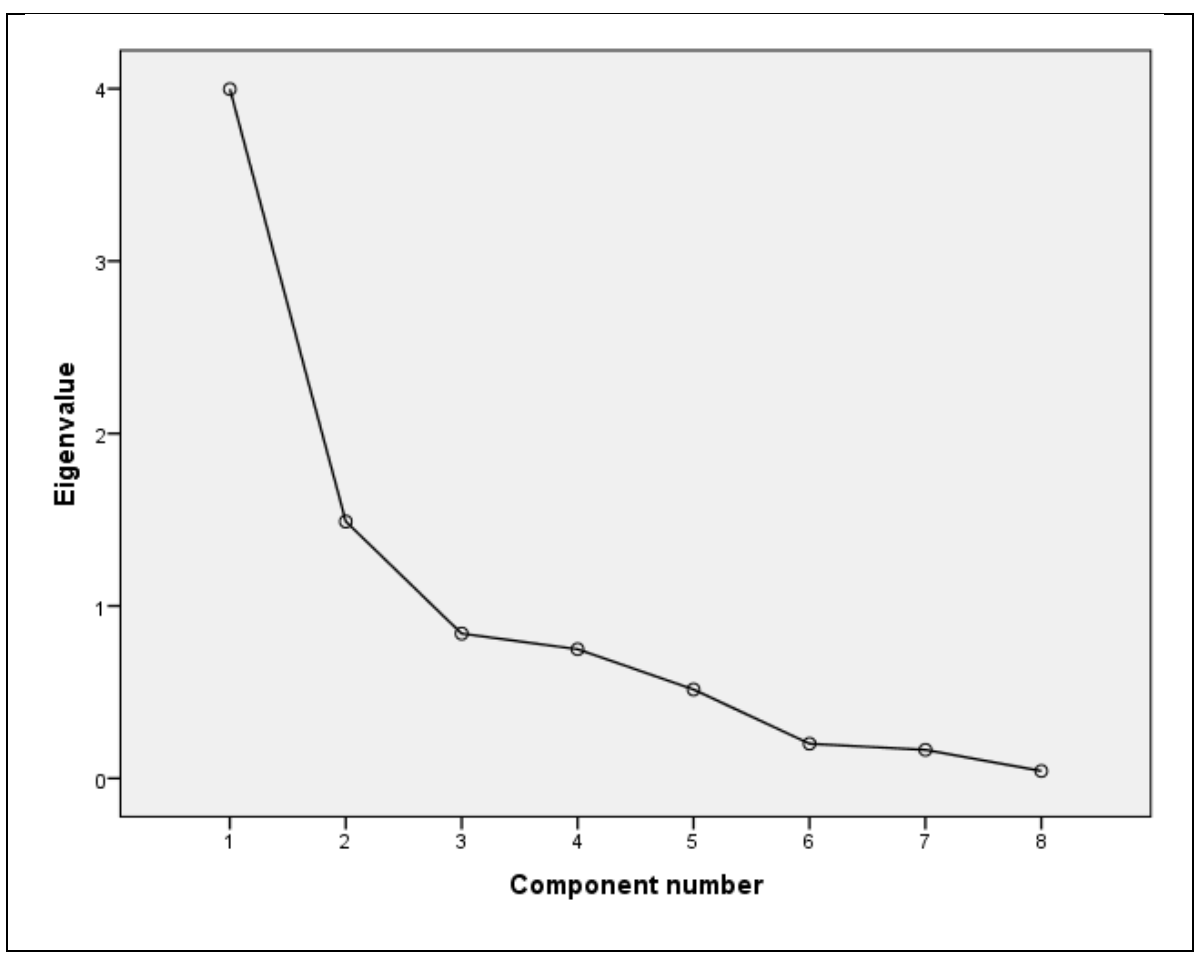

In Table 5 we present the component loadings in order to label the reduced two dimensions. We have applied Varimax rotation to facilitate the interpretation of the components. All variables, except the ranking regarding the average growth of the expenditure per tourist, total expenditure and inbound expenditure per GDP, obtain high loadings in the first dimension. As a result, the first dimension better captures the aspects reflecting the development of tourist activity, whereas the second dimension those more related to tourism expenditure and tourism profitability. Therefore we label 
the first dimension as "tourism development and economic growth", and the second as "tourism expenditure and profitability of tourism activity".

Table 5

Rotated component loadings - CATPCA

\begin{tabular}{l|cc}
\hline \multirow{1}{*}{ Position } & \multicolumn{2}{c}{ Dimension } \\
\cline { 2 - 3 } Expenditure per tourist & $\mathbf{1}$ & $\mathbf{2}$ \\
Overnight visitors & -0.233 & 0.967 \\
Total expenditure & 0.973 & 0.184 \\
Inbound expenditure per GDP & 0.415 & 0.910 \\
Rooms & 0.801 & -0.011 \\
Occupancy & 0.966 & 0.227 \\
GDP & 0.975 & 0.191 \\
HDI & 0.974 & 0.170 \\
\hline
\end{tabular}

Note: $\quad$ Rotation method: Varimax with Kaiser normalisation. Component loadings indicate Pearson correlations between the quantified variables and the principal components (ranging between -1 and 1$)$.

Table 6

Multivariate analysis - Summary

\begin{tabular}{|c|c|c|c|}
\hline \multicolumn{4}{|c|}{ CATPCA Model } \\
\hline \multirow{2}{*}{ Dimension } & \multirow{2}{*}{$\begin{array}{c}\text { Cronbach's } \\
\text { alpha }\end{array}$} & \multicolumn{2}{|c|}{ Variance } \\
\hline & & Total (eigenvalue) & $\%$ of variance \\
\hline 1 & 0.92 & 4.82 & 60.22 \\
\hline 2 & 0.80 & 2.74 & 34.26 \\
\hline Total & 0.99 & 7.56 & 94.48 \\
\hline \multicolumn{4}{|c|}{ MDS Model } \\
\hline Stress & 0.14 & RSQ & 0.90 \\
\hline
\end{tabular}

Notes: *Cronbach's alpha mean is based on the mean of the eigenvalue. Rotation method: Varimax with Kaiser normalisation. Kruskal's stress values indicate the amount of distortion in distances to tolerate. Stress values range from zero to one, zero indicating a perfect representation of the input data in two dimensions. The RSQ stands for the squared correlations in distances. RSQ values are the proportion of variance of the scaled data (disparities) in the partition which is accounted for by their corresponding distances.

In Table 6 we present a summary of the models. The first two factors obtained with

CATPCA account for almost $95 \%$ of the variance of the variables under analysis,

indicating the goodness of fit of the components. Figures 3 and 4 are two-dimensional scatterplots that represent the coordinates of the first two dimensions for each destination. 
Fig. 3. Biplot with rotated component loadings and objects - CATPCA

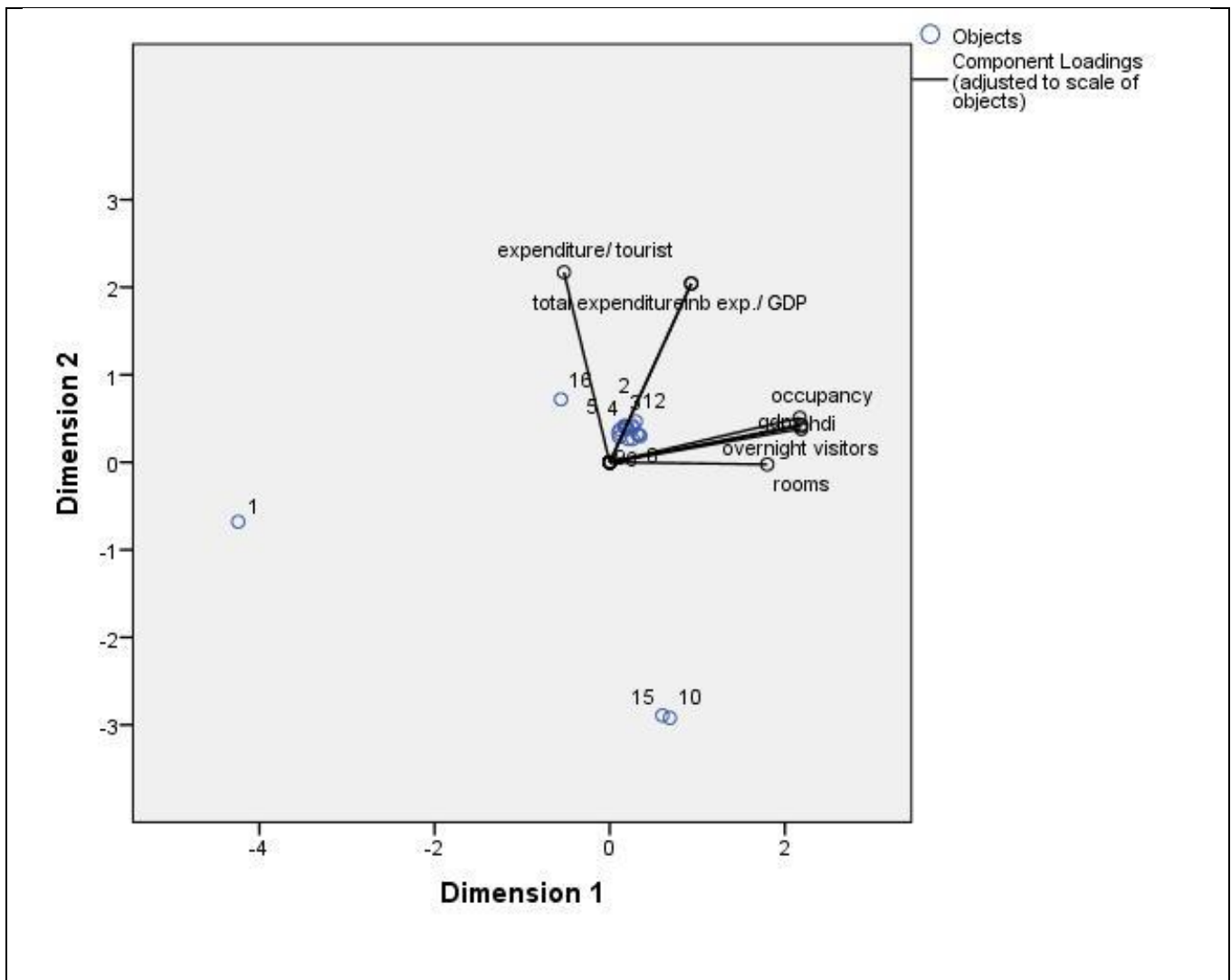

Note: $\quad$ Rotation method: Varimax with Kaiser normalisation. For visual clarity, we have coded each country with a number: Cambodia (1), Chile (2), Costa Rica (3), Dominican Republic (4), Egypt (5), El Salvador (6), Estonia (7), Finland (8), Greece (9), Hong Kong (10), Indonesia (11), Israel (12), Morocco (13), Norway (14), Panama (15), Philippines (16), Poland (17), Singapore (18), Sweden (19), and Tunisia (20).

Fig. 4. Perceptual map - MDS

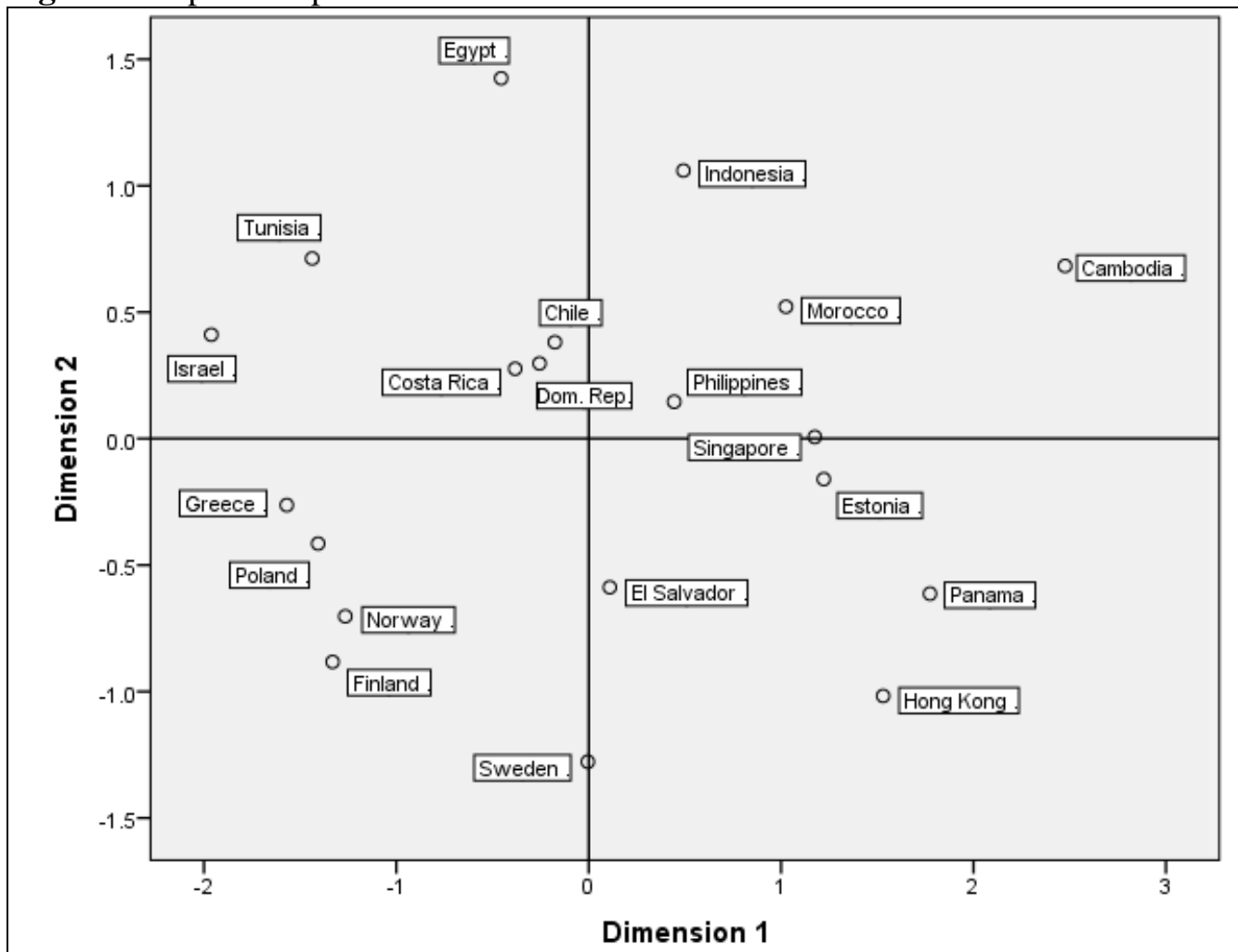


Fig. 3 shows the biplot projecting the two dimensions obtained with a CATPCA, and Fig. 4 the perceptual map projecting the first two dimensions obtained by means of MDS. Along both dimensions the biplot in Fig. 3 overlaps the object scores (destinations), and the component loadings (indicators). The coordinates of the end point of each vector are given by the loadings of each variable on the two components. Long vectors are indicative of a good fit. The variables that are close together in the plot, are positively related; the variables with vectors that make approximately a $180^{\circ}$ angle with each other, are closely and negatively related; finally, variables that are not related correspond with vectors making a $90^{\circ}$ angle.

In Fig. 3 we can observe that the first dimension captures more variance than the second dimension, both among the items and the cases. The rankings regarding overnight visitors, occupancy, GDP and HDI tend to coalesce together, indicating a close and positive relation between them, but no relation with the ranking regarding the expenditure per tourist, which stands apart. The rankings regarding inbound expenditure over GDP and total expenditure also coalesce together, and are unrelated to the ranking regarding the growth in rooms.

The perceptual map in Fig. 4 is divided in four quadrants. In the first top right quadrant, the Philippines, Indonesia and Cambodia are grouped together with Morocco. In the lower right quadrant, Hong Kong is grouped together with Panama, El Salvador and Estonia. Singapore falls in between these two quadrants. In the next quadrant to the left, the three Scandinavian countries (Finland, Norway and Sweden) are grouped together with Poland and Greece. Finally, in the last quadrant, Chile, the Dominican Republic and Costa Rica are grouped close together in one corner, as well as Israel, Egypt and Tunisia, which are grouped slightly apart.

Hence, the five Asia Pacific destinations fall into two main groups. On the one hand, Hong Kong and Singapore, on the other hand, Indonesia, the Philippines, and Cambodia, which is situated far from all the other countries (Fig. 3). Cambodia is the destination that presents the highest average annual growth rates for all variables except expenditure per tourist (Table 4). This persistent growth of the tourism industry in Cambodia poses profound challenges, especially in terms of profitability. Chens et al. (2008) found that in spite of Cambodia's endowed resources, the country needed supporting factors to increase its competitiveness.

Both techniques depict a similar positioning of the destinations with respect of the rankings in Table 4 . The groupings are also consistent with the results of the descriptive 
analysis in Section 3. This evidence adds to previous studies by Yau \& Chan (1990), Huang \& Peng (2012), and Assaf \& Tsionas (2015). By means of official tourism and economic information, we obtain similar results to those of Assaf \& Tsionas (2015), who ranked 101 countries according to 20 indicators of quality grouped in three dimensions (infrastructure, human resources and nature), and found that based on overall quality, Singapore is the best positioned of the five destinations, followed by Hong Kong, the Philippines, Indonesia, and Cambodia.

Yau \& Chan (1990) used MDS to map seven cities of the Asia and the Pacific region regarding prices and range of activities, finding that the market position of Singapore was close to that of Hong Kong. By means of six assessment criteria for destination competitiveness, Huang \& Peng (2012) found that the Philippines were ranked the lowest of six Asia Pacific destinations in terms of attractions, services, image and stability, but were the top destination for affordability, as opposed to Hong Kong, and Singapore. Li et al. (2013) calculated price elasticities, and found that Singapore was more competitive than Hong Kong.

These results show the potential of dimensionality reduction and data visualization techniques for exploratory data analysis, as well as their applicability as tools for the identification of key attributes in the positioning of tourism destinations.

\section{Summary and concluding remarks}

This study assesses the performance of data visualization techniques for the positioning of tourism destinations. We compare the performance of CATPCA and MDS. These techniques allow to generate two-dimensional visual representations of large datasets. Perceptual maps capture the strengths and weaknesses of destinations, and allow visualizing the similarity between them. We aim to provide managers with a methodology to map destinations regarding the evolution of their main tourism and economic indicators.

First, we analysed the interactions between official tourism and economic indicators in some of the world's emerging destinations during the years preceding and after the 2008 financial crisis. We observed that the evolution of overnight visitors and worldwide inbound tourism seems positively correlated in most destinations, and that total inbound expenditure over GDP also shows positive co-movements with respect of the expenditure per tourist in all destinations. Due to their heterogeneity, the five Asia 
Pacific destinations analysed in this research (Cambodia, Hong Kong, Indonesia, the Philippines, and Singapore), showed very different paths in the evolution of the growth rates of the main tourism and economic indicators.

Secondly, destinations were ranked according to the average annual growth experienced over the sample period for each variable. By means of two dimensionality reduction techniques for categorical data, we summarized all the information into two components: "tourism development and economic growth" and "tourism expenditure and profitability of tourism activity". Hence, we positioned the five Asia Pacific destinations with respect to other fifteen countries, and obtained different groups. Cambodia, Indonesia and the Philippines are grouped together. Hong Kong, with the highest position in relation to the profitability growth of tourism, is clustered apart, close to Singapore, which fell between the two groups. This result shows that in order to maximize tourism's full economic potential and to attain a sustainable tourism development, emerging destinations such as Cambodia, Indonesia and the Philippines, should increase the emphasis on tourism profitability.

The proposed methodology facilitates the identification of attributes that are the most relevant in positioning tourism destinations. The fact that the presented approach is easy to implement, makes it a useful tool for monitoring the evolution of destination competitiveness in an ever-changing tourism market. Nevertheless, this is is a descriptive study, and inference cannot be made. Either for lack of data, or the existence of outliers, there have been several issues left for further research. An independent analysis by purpose of travel and the inclusion of additional tourism indicators, such as the contribution of tourism to employment or the average expenditure per day, would give further insight into the profitability and the contribution of tourism development to economic growth. On the other hand, another question left for future research is the implementation and assessment of artificial intelligence techniques such as selforganizing maps in the positioning of the destinations.

\section{Acknowledgements}

We would like to thank the Editor and two anonymous referees for their useful comments and suggestions. We wish to thank Laura Muñoz and Jacinta García at the World Tourism Organization (UNWTO) for providing us with the data used in this study. This paper has been partially financed by the project ECO2016-75805-R of the Spanish Ministry of Economy and Competitiveness. 


\section{References}

Andreu, L., Bigné, J. E., \& Cooper, C. (2000). Projected and perceived image of Spain as a tourist destination for British travellers. Journal of Travel and Tourism Marketing, 9(4), 47-67.

Arimond, G., \& Elfessi, A. (2001). A clustering method for categorical data in tourism market segmentation research. Journal of Travel Research, 39(4), 391-397.

Assaf, A. G., \& Tsionas, E. G. (2015). Incorporating destination quality into the measurement of tourism performance: A Bayesian approach. Tourism Management, $49,58-71$.

Au, A. K. M., Ramasamy, B., \& Yeung, M. C. H. (2005). The effects of SARS on the Hong Kong tourism industry: An empirical evaluation. Asia Pacific Journal of Tourism Research, 10(1), 85-95.

Balaguer, J., \& Cantavella-Jordá, M. (2002). Tourism as a long-run economic growth factor: The Spanish case. Applied Economics, 34(7), 877-884.

Bao, Y. F., \& Mckercher, B. (2008). The effect of distance on tourism in Hong Kong: A comparison of short haul and long haul visitors. Asia Pacific Journal of Tourism Research, 13(2), 101-111.

Bloom, J. Z. (2005). Market segmentation: A neural network application. Annals of Tourism Research, 32(1), 93-111.

Borg, I., \& Groenen, P. J. F. (2005). Modern multidimensional scaling: Theory and applications (2nd Ed.). New York: Springer-Verlag.

Borg, I., Groenen, P. J. F., Patrick, M. (2013). Applied multidimensional scaling. Berlin: Springer-Verlag.

Brida, J. G., Cortes-Jimenez, I., \& Pulina, M. (2016). Has the tourism-led growth hypothesis been validated? A literature review. Current Issues in Tourism, 19(5), 394-430.

Capó, J., Riera, A., \& Rosselló, J. (2007). Tourism and long-term growth. A Spanish perspective. Annals of Tourism Research, 34(3), 709-726.

Chandra, S., \& Menezes, D. (2001). Applications of multivariate analysis in international tourism research: The marketing strategy perspective of NTOs. Journal of Economic and Social Research, 3(1), 77-98.

Chens, C. Y., Sok, P., \& Sok, K. (2008). Evaluating the competitiveness of the tourism industry in Cambodia: Self-assessment from professionals. Asia Pacific Journal of Tourism Research, 13(1), 41-66.

Chheang, V. (2008). The political economy of tourism in Cambodia. Asia Pacific Journal of Tourism Research, 13(3), 281-297.

Chhetri, P., Arrowsmith, C., \& Jackson, M. (2004). Determining hiking experiences in nature-based tourism destinations. Tourism Management, 25(1), 31-43.

Choi, W. M., Chan, A., \& Wu, J. (1999). A qualitative and quantitative assessment of Hong Kong's image as a tourist destination. Tourism Management, 20(3), 361-365.

Chou, M. C. (2007). Does tourism development promote economic growth in transition countries? A panel data analysis. Economic Modelling, 33, 226-232.

Chu, H. P., Yeh, M. L., \& Chang, T. Y. (2014). Are visitor arrivals to China stationary? An empirical note. Asia Pacific Journal of Tourism Research, 19(2), 248-256.

Claveria, O., Monte, E., \& Torra, S. (2016). A self-organizing map analysis of surveybased agents' expectations before impending shocks for model selection: The case of the 2008 financial crisis. International Economics, 146, 40-58. 
Claveria, O., \& Poluzzi, A. (2017). Positioning and clustering of the world's top tourist destinations by means of dimensionality reduction techniques for categorical data. Journal of Destination Marketing \& Management. In Press.

Correia, A., Oom do Valle, P., \& Moço, C. (2007). Modeling motivations and perceptions of Portuguese tourists. Journal of Business Research, 60(1), 76-80.

Cortes-Jimenez, I., Nowak, J., \& Sahli, M. (2011). Mass beach tourism and economic growth: Lessons from Tunisia. Tourism Economics, 17(3), 531-547.

Croes, R. (2011). Measuring and explaining competitiveness in the context of small island destinations. Journal of Travel Research, 50(4), 431-442.

Crompton, J. L., Fakeye, P. C., \& Lue, C. (1992). Positioning: The example of the Lower Rio Grande Valley in the winter long stay destination market. Journal of Travel Research, 31, 20-26.

Crouch, G. I., \& Ritchie, J. R. B. (1999). Tourism, competitiveness and social prosperity. Journal of Business Research, 44(3), 137-152.

Crouch, G., \& Ritchie, J. R. B. (2006). Competitiveness and tourism. In L. Dwyer \& P. Forsyth (Eds.), International Handbook on the Economics of Tourism (pp. 419-433). Cheltenham: Edward Elgar Publishing.

Dwyer, L., Forsyth, P., \& Dwyer, W. (2010). Tourism Economics and Policy. Bristol: Channel View Publications.

Durbarry, R. (2004). Tourism and economic growth: the case of Mauritius. Tourism Economics, 10(4), 389-401.

Fentom, M., \& Pearce, P. (1988). Multidimensional scaling and tourism research. Annals of Tourism Research, 15, 236-254.

Gartner, W. C. (1989). Tourism image: Attribute measurement of state tourism products using multidimensional scaling techniques. Journal of Travel Research, 28, 16-20.

Gifi, A. (1990). Nonlinear multivariate analysis. Chichester, England: Wiley.

Green, R. (2005). Community perceptions of environmental and social change and tourism development on the island of Koh Samui, Thailand. Journal of Environmental Psychology, 25(1), 37-56.

Guttman, L. (1954). Some necessary and sufficient conditions for common factor analysis. Psychometrika, 19(2), 149-161.

Gursoy, D., Baloglu, S., \& Chi, C. G. (2009). Destination competitiveness of Middle Eastern countries: An examination of relative positioning. Anatolia, 20(1), 151-163.

Haahti, A. J. (1986). Finland' s competitive position as a destination. Annals of Tourism Research, 13(1), 11-35.

Hair, J. F., Black, W. C., Babin, B. J., \& Anderson, R. E. (2009). Multivariate data analysis (7th Ed.). Upper Saddle River, NJ: Prentice Hall.

Hassan, S.S. (1954). Determinants of market competitiveness in an environmentally sustainable tourism industry. Journal of Travel Research, 38, 239-245.

Hastie, T., \& Stuetzle, W. (1989). Principal curves. Journal of the American Statistical Association, 84 (406), 502-516.

Heung, V. C. S., \& Qu, H. (1998). Tourism shopping and its contributions to Hong Kong. Tourism Management, 19(4), 382-385.

Horng, J. S., \& Tsai, C. T. (2012). Exploring marketing strategies for culinary tourism in Hong Kong and Singapore. Asia Pacific Journal of Tourism Research, 17(3), 277300.

Huang, J. H., \& Peng, K. H. (2012). Fuzzy Rasch model in TOPSIS: A new approach for generating fuzzy numbers to assess the competitiveness of the tourism industries in Asian countries. Tourism Management, 33(2), 456-465.

Jolliffe, I. T. (2002). Principal component analysis (2nd Ed.). Springer Series in Statistics. 
Kaiser, H. F. (1960). The application of electronic computers to factor analysis. Educational and Psychological Measurement, 20, 141-151.

Kayar, C. H., \& Kozak, N. (2010). Measuring destination competitiveness: An application of the Travel and Tourism Competitiveness Index (2007). Journal of Hospitality Marketing \& Management, 19(3), 203-216.

Kim, H. (1998). Perceived attractiveness of Korean destinations. Annals of Tourism Research, 25(2), 340-361.

Kim, S. S., \& Agrusa, J. (2005). The positioning of overseas honeymoon destinations. Annals of Tourism Research, 32(4), 887-904.

Kim, S. S., Chun, H., \& Petrick, J. F. (2005). Positioning analysis of overseas golf tour destinations by Korean golf tourists. Tourism Management, 26(6), 905-917.

Kohonen T. (2001). Self-organizing maps. Springer: Berlin.

Kramer, M. A. (1991). Nonlinear principal component analysis using autoassociative neural networks. AIChE Journal, 37(2), 233-243.

Law, R., \& Au, V. M. (1999). A neural network model to forecast Japanese demand for travel to Hong Kong. Tourism Management, 20(1), 89-97.

Lee, K., \& Ha, I. S. (2012). Exploring the impacts of key economic indicators and economic recessions in the restaurant industry. Journal of Hospitality Marketing \& Management, 21 (3), 330-343.

Leung, X. Y., \& Baloglu, S. (2013). Tourism competitiveness of Asia Pacific destinations. Tourism Analysis, 18(4), 371-384.

Li, X. (Robert), Cheng, C., Kim, H., \& Li, X. (2015). Positioning USA in the Chinese outbound travel market. Journal of Hospitality \& Tourism Research, 39(1), 75-104.

Li, G., Song, H., Cao, Z., \& Wu, D. C. (2013). How competitive is Hong Kong against its competitors? An econometric study. Tourism Management, 36, 247-256.

Linting, M., Meulman, J. J., Groenen, P. J. F., \& Van der Kooij, A. J. (2007). Nonlinear principal component analysis: Introduction and application. Psychological Methods, 12(3), 336-358.

Liu, Y., \& Weisberg, R. H. (2005). Patterns of ocean current variability on the west Florida shelf using the self-organizing map. Journal of Geophysical Research, 110(C6), 1-12.

Lo, A., Cheung, C., \& Law, R. (2006). The survival of hotels during disaster: A case study of Hong Kong in 2003. Asia Pacific Journal of Tourism Research, 11(1), 6580.

Lozano, S., \& Gutiérrez, E. (2011). Efficiency analysis of EU-25 member states as tourist destinations. International Journal of Services Technology and Management, $15(1 / 2), 69-88$.

Maguigad, V. M. (2013). Tourism planning in archipelagic Philippines: A case review. Tourism Management Perspectives, 7, 25-33.

Marcussen, C. H. (2011). Visualising groups of European destinations. European Journal of Travel Research, 4(2), 180-190.

Marcussen, C. H. (2014). Multidimensional scaling in tourism literature. Tourism Management Perspectives, 12, 31-40.

Meng, X., Siriwardana, M., \& Pham, T. (2013). A CGE assessment of Singapore's tourism policies. Tourism Management, 34, 25-36.

Meulman, J. J., Heiser, W. J., \& SPSS. (2012). SPSS Categories 20.0. Chicago, Illinois: SPSS.

Mohammed, I., Guillet, B. D., \& Law, R. (2015). The contributions of economics to hospitality literature: A content analysis of hospitality and tourism journals. International Journal of Hospitality Management, 44, 99-110. 
Novak, M., Petrić, L., \& Pranić, L. (2011). The effects of selected macroeconomic variables on the presence of foreign hotels in Croatia. Tourism and Hospitality Management, 17 (1), 45-65.

Nowak, J., Sahli, M., \& Cortes-Jimenez, I. (2007). Tourism, capital goods imports and economic growth: theory and evidence for Spain. Tourism Economics, 13(4), 515536.

Okumus, B., Okumus, F., \& Mckercher, B. (2007). Incorporating local and international cuisines in the marketing of tourism destinations: The cases of Hong Kong and Turkey. Tourism Management, 28(1), 253-261.

Oh, C. O. (2005). The contribution of tourism development to economic growth in the Korean economy. Tourism Management, 26(1), 39-44.

Omerzel, D. G. (2006). Competitiveness of Slovenia as a Tourist Destination. Managing Global Transitions, 4(2), 167-189.

Pambudi, D., McCaughey, N., \& Smyth, R. (2009). Computable general equilibrium estimates of the impact of the Bali bombing on the Indonesian economy. Tourism Management, 30(2), 232-239.

Park, D. B., \& Yoon, Y. S. (2009). Segmentation by motivation in rural tourism: A Korean case study. Tourism Management, 30(1), 99-108.

Pérez-Rodríguez, J. V., Ledesma-Rodríguez, F., \& Santana-Gallego, M. (2015). Testing dependence between GDP and tourism's growth rates. Tourism Management, 48, 268-282.

Pike, S. (2002). Destination image analysis - A review of 142 papers from 1973 to 2000. Tourism Management, 23(5), 541-549.

Pranić, L., Ketkar, S., \& Roehl, W. S. (2012). The impact of macroeconomic countryspecific factors on international expansion of US hotel chains. Tourismos, 7 (1), 155173.

Prideaux, B., Laws, E., \& Faulkner, B. (2003). Events in Indonesia: exploring the limits to formal tourism trends forecasting methods in complex crisis situations. Tourism Management, 24(4), 475-487.

Qu, H., Li, L., \& Chu, G. K. T. (2000). The comparative analysis of Hong Kong as an international conference destination in Southeast Asia. Tourism Management, 21(6), 643-648.

Reimer, J. K., \& Walter, P. (2013). How do you know it when you see it? Communitybased ecotourism in the Cardamom Mountains of southwestern Cambodia. Tourism Management, 34, 122-132.

Roxas, B., \& Chadee, D. (2013). Effects of formal institutions on the performance of the tourism sector in the Philippines: The mediating role of entrepreneurial orientation. Tourism Management, 37, 1-12.

Santana-Gallego, M., Ledesma-Rodríguez, F. J., \& Pérez-Rodríguez, J. V. (2010). Exchange rate regimes and tourism. Tourism Economics, 16(1), 25-43.

Santana-Gallego, M., Ledesma-Rodriguez, F. J., \& Perez-Rodriguez, J. V. (2011). Tourism and trade in small island regions: The case of the Canary islands. Tourism Economics, 17(1), 107-125.

Sarlin, P., \& Peltonen, T. A. (2013). Mapping the state of financial stability. Journal of International Financial Markets, Institutions \& Money, 26, 46-76.

Schölkopf, B., Smola, A. J., \& Müller, K. (1988). Nonlinear component analysis as a kernel eigenvalue problem. Neural Computation, 10(5), 1299-1319.

Schubert, S. F., \& Brida, J. G. (2009). Macroeconomic effects of changes in tourism demand: A simple dynamic model. Tourism Economics, 15(3), 591-613.

Schubert, S. F., Brida, J. G., \& Risso, W. A. (2011). The impacts of international tourism demand on economic growth of small economies dependent on tourism. Tourism Management, 32, 377-385. 
Seo, J. H., Park, S. Y., \& Boo, S. (2010). Interrelationships among Korean outbound tourism demand: Granger causality analysis. Tourism Economics, 16(3), 597-610.

Singh, A., Dev, C. S., \& Mandelbaum, R. (2014). A flow-through analysis of the US lodging industry during the great recession. International Journal of Contemporary Hospitality Management, 26(2), 205-224.

Song, H., Dwyer, L., Li, G., \& Cao, Z. (2012). Tourism economics research: A review and assessment. Annals of Tourism Research, 39(3), 1653-1682.

Song, H., Lin, S., Witt, S. F., \& Zhang, X. (2011). Impact of financial/economic crisis on demand for hotel rooms in Hong Kong. Tourism Management, 32(1), 172-186.

Tang, X. (2017). The historical evolution of China's tourism development policies (1949-2013) - A quantitative research approach. Tourism Management, 58, 259269.

Torgerson, W. S. (1952). Multidimensional scaling: I. Theory and method. Psychometrika, 17(4), 401-419.

UNWTO (2015). UNWTO Tourism highlights, 2015 Edition. UNWTO (http://www.eunwto.org/doi/book/10.18111/9789284416899).

Uysal, M., Chen, J., \& Williams, D. R. (2000). Increasing state market share through a regional positioning. Tourism Management, 21(1), 89-96.

Yau, O. H. M., \& Chan, C. F. (1990). Hong Kong as a travel destination in South-East Asia: A multidimensional approach. Tourism Management, 11(2), 123-132.

Ye, B. H., Qiu, H. Z., \& Yuen, P. P. (2011). Motivations and experiences of Mainland Chinese medical tourists in Hong Kong. Tourism Management, 32(5), 1125-1127.

Yeomans, K. A., \& Golder, P. A. (1982). The Guttman-Kaiser criterion as a predictor of common factors. Journal of the Royal Statistical Society. Series D (The Statistician), 31(3), 221-229.

Wang, Y. S. (2009). The impact of crisis events and macroeconomic activity on Taiwan's international inbound tourism demand. Tourism Management, 30(1), 7582.

Wish, M., Deutsch, M., \& Biener, L. (1970). Differences in conceptual structures of nations: An exploratory study. Journal of Personality and Social Psychology, 16(3), 361-373.

Wong, K. N., \& Tang, T. C. (2010). Tourism and openness to trade in Singapore: Evidence using aggregate and country-level data. Tourism Economics, 16(4), 965980.

Wong, J., \& Law, R. (2003). Difference in shopping satisfaction levels: A study of tourists in Hong Kong. Tourism Management, 24(4), 401-410.

WTTC (2014). WTTC Travel \& tourism economic impact 2014. Cambodia. World Travel \& Tourism Council.

WTTC (2015). WTTC Travel \& tourism economic impact 2014. Hong Kong. World Travel \& Tourism Council.

Zins, A. H. (2010). Mapping beneficial destination images. Journal of Hospitality and Tourism Management, 17, 96-107. 